\title{
Forest Characterization in the Central Plateau of Yellowstone National Park USing MUltispeCtral High RESOLUTiON Digital Photography
}

\author{
M.E. JAKUBAUSKAS $\downarrow$ LUDMILA MONIKA MOSKAL $\downarrow$ M.E. HOUTS \\ K. PRICE $\uparrow$ E. MARTINKO \\ KANSAS APPLIED REMOTE SENSING PROGRAM \\ UNIVERSITY OF KANSAS — LAWRENCE
}

\begin{abstract}
$\uparrow \quad$ ABSTRACT
Detailed knowledge of forest structure is an important component in research focusing on forest biodiversity monitoring, carbon budgeting studies, fire modeling and forest inventory estimation. In forest inventory mapping, high spatial resolution multispectral imagery are becoming a valuable and often a critical tool to effective resource management planning. In this report, we describe and illustrate the forestry applications of a multispectral digital imaging camera sy stem (DuncanTech MS3100) that was experimentally flown over several study areas in the Central Plateau of Yellowstone National Park, in July, 2001. The purpose of this demonstration is three fold; first we will apply geostatistical methods, co-kriging specifically, to model forest canopy components such as height, canopy thickness, species, density and structure; second, we will examine the spectral and spatial characteristics of seedling regeneration in the 1988 burn sites; finally, forest stand characteristics such as stem counts, crown species and amount of deadfall (potential fire fuel) will be estimated for selected sites. Our results will be compared to information acquired from coarser resolution, multispectral Landsat TM data obtained on the same date.
\end{abstract}

\section{INTRODUCTION}

Accurate mapping of forest successional stages, structure, or cover types, is critical for fire behaviour prediction, animal habitat management carbon budgeting studies, and preservation of biodiversity (Knight and Wallace, 1989). Resource managers traditionally use field and photo interpretation methods for mapping vegetation, but these techniques are time consuming, expensive, and inherently subjective. Landsat TM data enable forest condition monitoring and mapping over a large geographic region in a consistent and replicable manner. In forest inventory mapping, high spatial resolution multispectral imagery is becoming a valuable and often a critical tool to effective resource management planning. Furthermore, aerial sensors allow a more detailed look at specific areas of interest, and can even provide a means of calibration for predictive models built on using Landsat TM data. Here, we describe and illustrate the forestry applications of a multispectral digital imaging camera system (Duncan Tech MS3100) that was experimentally flown over several study areas in the Central Plateau of Yellowstone National Park, in July, 2001. The purpose of this demonstration is three fold; to apply geostatistical methods, 
co-kriging specifically, to model forest canopy components such as height, canopy thickness, species, density and structure; estimate forest stand characteristics such as stem counts, crown diameter and species and amount of deadfall (potential fire fuel), and; examine the spectral and spatial characteristics of seedling regeneration in the 1988 burn.

\section{$\uparrow \quad$ STUdY AREA}

The Central Plateau of Yellowstone National Park (Figure 1) provides ideal conditions for studying the spectral reflectance characteristics of coniferous forests for several reasons. First, the ecology and succession of the Yellowstone forest have been well documented (Despain, 1990; Romme, 1989). Second, much of the Yellowstone coniferous forest occurs as a mosaic of succession stages on extensive, gently rolling plateaus. The forest canopy of Yellowstone is dominated by lodgepole pine ( $83 \%$ of the canopy), minimizing variations potentially introduced by mixtures of tree species, in particular mixtures of coniferous and deciduous trees.
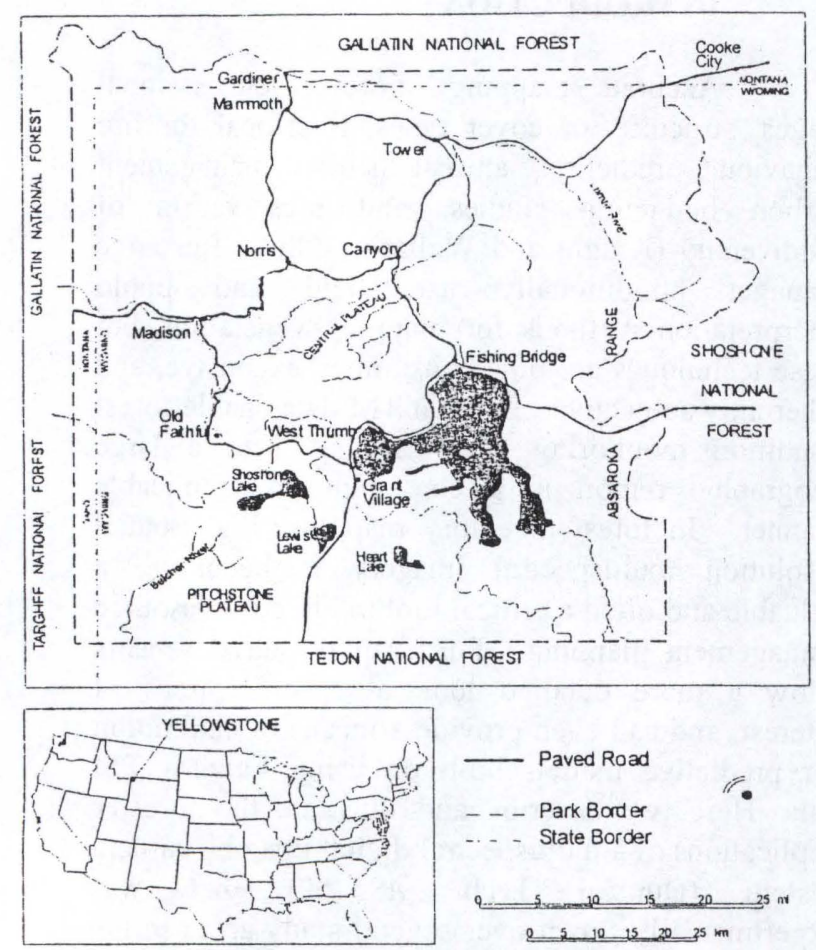

Figure 1. The central plateau of Yellowstone National Park.

\section{METHODS}

A customized DuncanTech MS3100 digital multispectral c amera was used to collect $40 \mathrm{~cm}$ per pixel resolution imagery over two study sites in the Central Plateau of Yellowstone National Park, between July 18 and 20,2001 . The three spectral bands collected were blue $(450-520 \mathrm{~nm})$ red $(630-$ $690 \mathrm{~nm})$ and near-infrared $(760-900 \mathrm{~nm}) . \quad A$ progressive scan was used to acquire clear images of moving targets at frame rates of up to $7.5 \mathrm{fps}$. The image data was captured from the digital camera using National Instrument's PCI-1424 Frame Grabber. The camera's output provided parallel pixel data, pixel clock, line valid, and frame valid signals. The digital frame grabber was connected to the digital video output connector on the camera using a 100-pin data cable. A 600Mhz Pentium III computer with $128 \mathrm{Mb}$ RAM and running Windows 98 was used to control camera configuration and image acquisition software. While in flight, the system saved c aptured imagery to a $75 \mathrm{~Gb}$ h ard drive. The computer also had a CD-R drive for more permanent storage of the imagery. A Sony 15 -inch TFT LCD color monitor was used to view input from either the computer or camera using a video with a resolution of1024x768@75Hz, this monitor a lso had high contrast that allows images to be viewed under bright cockpit conditions. The power supply for the computer and camera consisted of a self-contained power supply system which was constructed using two 12 volt deep-cycle batteries and a Whistler $1500 \mathrm{~W}$ DC to AC power inverter. The power supply included a digital voltmeter and an emergency power disconnect sw itch. T he computer, c amera, inverter, and monitor were mounted to a wooden pallet and connected together. The batteries were mounted on a separate pallet and automotive battery cables used to connect the batteries to the inverter. After determining available mount points in the single engine Cessna 172 airplane (Figure 2), holes were drilled in the pallet and the pallets secured to the rear seat rails on the floor of the aircraft. The camera, mounted on a standard camera tripod, was positioned over a hole cut in the bottom of the airplane and secured with nylon straps. The passenger controlled the entire imagery acquisition process using a mini keyboard with touch pad mouse. The imaging area was 1392 X 1040 pixels or approximately 0.4 by 0.5 $\mathrm{km}$ on the ground. Over 20 flight lines (Figure 3) were required to cover the West Thumb area of interest shown in Figure 3. 


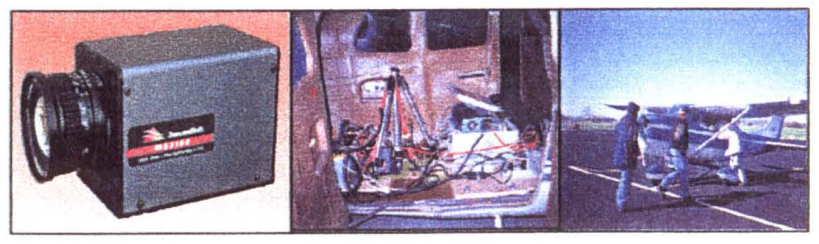

Figure 2. The DuncanTech digital multispectral camera and configuration in KU Cessna.
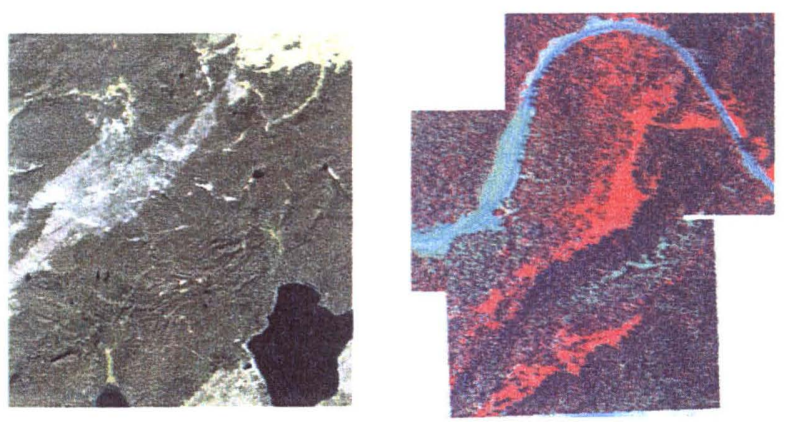

Figure 3. (Left): Landsat Thematic Mapper image of southern Central Plateau study area; Right): Sample (three-image mosaic of DuncanTech airborne digital multispectral images of Central Plateau lodgepole pine forest.

\section{$\uparrow$ DISCUSSION}

\section{GEOSTATISTICAL METHODS}

Spatial analysis of forest digital imagery is based on the close link between forest canopy structure and image texture as well as on the relationship between the image pattern and the processes that take place in the scene. Different authors have concluded that tree size and density greatly influence the spatial structure of high resolution images of forest stands and that the variogram is an effective tool to measure this structure. Thus, the $40 \mathrm{~cm}$ per pixel imagery collected in the 21 flightlines (Figure 3) at the West Thumb area of the Central Plateau, Yellowstone National Park, can be used to extract forest stand characteristics such as per species basal area, tree height and canopy structure (roughness/thickness). Furthermore, geostatistical methods can be used to exploit the spatial information pertaining to forest structure inherent in image data. I By calibrating remotely sensed multi spectral data with a small number of ground measurements, and information extracted from the aerial sensor, characteristics of the forest measured at sample points can be extrapolated across a large geographic region. This has significant advantages for forest management, especially when forests are in remote or inaccessible locations. Thus, we plan to use the forest measurements and information obtained from the high resolution aerial sensor to develop robust geostatistical models

\section{ESTIMATING STAND CHARACTERISTICS}

Maximum likelihood supervised classification or unsupervised classification are not suitable for the analysis of very high resolution images such as those captured by high resolution aerial multispectral sensors. Thus, other methods that are specifically designed for high resolution sensors are becoming more essential to forest managers interested in the application of such data. In coniferous forests the top of the tree crown forms an apex that is illuminated more brightly then the surrounding branches. This apex is captured as a very bright pixel in high resolution imagery (Figure 4). By applying image filtering methods that capture this apex pixel, stem counts and per hectare forest densities can be estimated. Furthermore, object oriented image analysis, based on the concept that information necessary to interpret an image is not necessarily represented in single pixels, but in meaningful image objects and their mutual relationships, can be used for tree crown delineation. Using this approach these objects can be quantified, measured and compared to ground based measurements. Finally, these methods can be tested for deadfall estimation (Figure 5), which is one of the more important components of forest fire susceptibility modeling, under different forest conditions and crown densities.

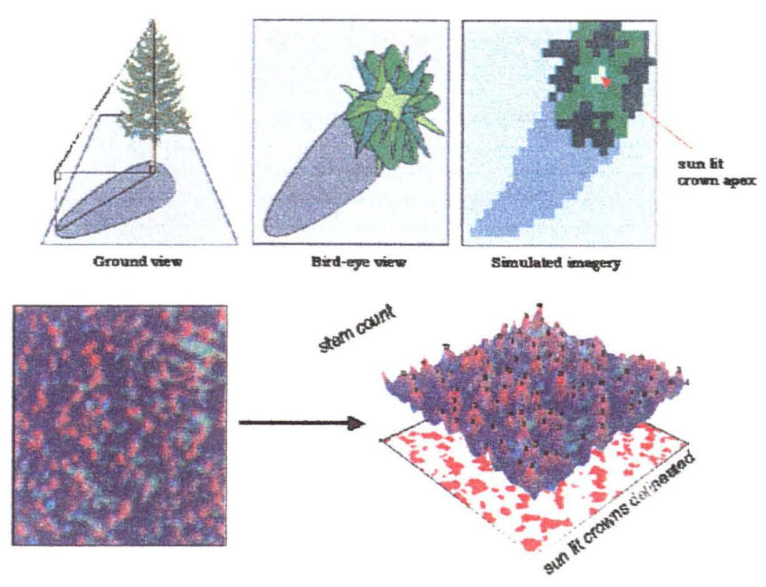

Figure 4. Object oriented stem count and crown diameter estimation from high-resolution digital multispectral aerial photography. 


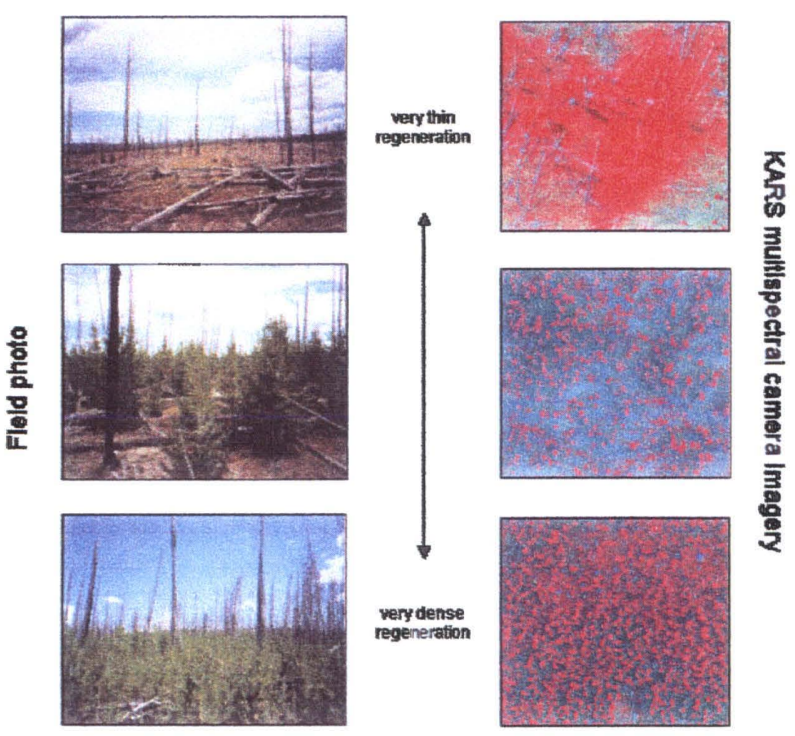

Figure 5. Typical seedling regeneration densities in Yellowstone National Park lodgepole forest and corresponding digital aerial multispectral imagery.

\section{SEEDLING REGENERATION}

The large fires of 1988 in Yellowstone demonstrated how dramatically and rapidly the vegetation and consequently the state of an ecosystem can change. The 250,000 ha of forest burnt in the 1988 fires creating a striking mosaic of burn severities on the landscape of the park. The burns have begun to naturally regenerate with lodgepole pine seedlings (Reed 1999). The influence of this regeneration on ecological processes affecting the fauna of that ecosystem will have an impact for decades to come (Norland 1996). Knowing where and how the burns are regenerating is an important aspect of sustainable park management strategies. Figure 5 demonstrated four seedling density regeneration sites. The presence of other vegetation in the very low seedling density regeneration site produces a similar spectral response to other seedling density sites. Thus, the redness in the aerial images indicates the presence of vegetation. However, the spatial component of the aerial data clearly differs for all four seedling density regeneration sites because the seedling crowns produce different spatial patterns. Therefore, spatial image information captured by image texture can be incorporated to improve the distinction between these different sites (Moskal 2001).

\section{$\uparrow \quad$ ACKNOWLEDGMENTS}

This project was conducted at the Kansas Applied Remote Sensing (KARS) Program (Edward
A. Martinko, Director). The research described in this paper was funded by the National Aeronautics and Space Administration (NASA) Earth Science Enterprise Food and Fiber Applications of Remote Sensing (FFARS), Project NAG13-99019. The authors would like to thank the Yellowstone 2001 field campaign team including Matt Dunbar, Dana Peterson, Andrea Repinsky and Dr. Mike Shaughnessy. Finally, acknowledgments are extended to the airborne data acquisition team: Ron Renz (Pilot), Michael Houts (KARS system operator), Dr. Mark Ewing, (University of Kansas Aerospace Engineering) and Dr. David Downing (Kansas NASA EPSCOR).

\section{LITERATURE SITED}

Despain, D. 1990. Yellowstone Vegetation: Consequences of Environment and History in a Natural Setting. Roberts Rinehart Publishers, Santa Barbara, 239 p.

Knight, D.H., and L.L. Wallace. 1989. The Yellowstone fires: issues in landscape ecology. BioScience 39:707-715.

Moskal, L.M., K.P. Price, M. E. Jakubauskas and E.A. Martinko, 2001. Comparison of hyperspectral AVIRIS and Landsat TM imagery for estimating burn site pine seedling regeneration densities in the Central Plateau of Yellowstone National Park. Proceedings of the $3^{\text {rd }}$ International Forestry and Agriculture Remote Sensing Conference and Exhibition, Denver, CO, November 2001.

Norland, J.E., F.J. Singer, L. Mack., 1996. Effects of the Yellowstone fires of 1988 on elk habitats. Pp. 223-232, In Ecological implications of fire in Greater Yellowstone. International Association of Wildland Fire, Fairfield, WA.

Reed, R. A., M. E. Finley, W. H. Romme and M. G. Turner, 1999. Aboveground net primary production and leaf area index in early postfire vegetation in Yellowstone National Park, Ecosystems, Vol. 2, pp. 88-94.

Romme, W.H. and D.G. Despain, 1989. Historical perspective on the Yellowstone Fires of 1988, Bioscience, Vol. 39, No.10, pp. 696699. 